\title{
Biomaterials
}

\section{Probing polydopamine adhesion to protein and polymer films: microscopic and spectroscopic evaluation}

\author{
David Mallinson ${ }^{1}$ (D), Alexander B. Mullen ${ }^{1}$ (D), and Dimitrios A. Lamprou ${ }^{1,2, \star}$ (]) \\ ${ }^{1}$ Strathclyde Institute of Pharmacy and Biomedical Sciences, University of Strathclyde, Cathedral Street, Glasgow G4 ORE, UK \\ ${ }^{2}$ Medway School of Pharmacy, University of Kent, Medway Campus, Anson Building, Central Avenue, Chatham Maritime, \\ Chatham, Kent ME4 4TB, UK
}

Received: 1 August 2017

Accepted: 8 November 2017

Published online:

15 November 2017

(C) The Author(s) 2017. This article is an open access publication

\begin{abstract}
Polydopamine has been found to be a biocompatible polymer capable of supporting cell growth and attachment, and to have antibacterial and antifouling properties. Together with its ease of manufacture and application, it ought to make an ideal biomaterial and function well as a coating for implants. In this paper, atomic force microscope was used to measure the adhesive forces between polymer-, protein- or polydopamine-coated surfaces and a silicon nitride or polydopamine-functionalised probes. Surfaces were further characterised by contact angle goniometry, and solutions by circular dichroism. Polydopamine was further characterised with infrared spectroscopy and Raman spectroscopy. It was found that polydopamine functionalisation of the atomic force microscope probe significantly reduced adhesion to all tested surfaces. For example, adhesion to mica fell from $0.27 \pm 0.7$ to $0.05 \pm 0.01 \mathrm{nN} \mathrm{nm}{ }^{-1}$. The results suggest that polydopamine coatings are suitable to be used for a variety of biomedical applications.
\end{abstract}

\section{Introduction}

The ideal coating for a biomedical device should be non-toxic, non-inflammatory, resistant to bacterial colonisation and support growth of host cells to improve integration [1]. The use of a coating allows the device interface to have favourable properties with the biological environment, even if the coating material is not the most appropriate for the core, exemplified by coated stainless steel cardiovascular stents which have appropriate biomechanical properties of the metal core. Additionally, a coating is particularly useful if it can be applied to the surface easily and uniformly. The mussel adhesive-inspired polydopamine (PD) appears to be an ideal biomaterial coating since it fulfils all these criteria. It exhibits low cytotoxicity [2], antibacterial properties [3, 4], promotes cell growth [5-8], resists corrosion [9], can aid antibiotic release [10, 11], is simple to produce

Address correspondence to E-mail: d.lamprou@kent.ac.uk 
with control over film thickness [12] and can be attached to a variety of surfaces including silanes [13], metals [9, 14], polymers [7, 15-17] dentine [18] and even hair [19].

Zhong et al. [20] found that while PD functionalisation of $\mathrm{TiO}_{2}$ nanotubes improved attachment, proliferation and nitric oxide release of endothelial cells, the same functionalisation reduced attachment and proliferation of smooth muscle cells. Despite promotion of cell attachment, modification of PD with polymer carpets, such as poly (3-sulphopropyl methacrylate) (PSPMA), can also be used to confer antifouling properties [8]. The ability to support cell attachment and growth is likely, at least partly, to be a result of its good hydrophilicity. For example, Hafner et al. [8] showed that PD nanosheets had a water contact angle $\left(\theta_{\mathrm{A}}\right)$ of $35^{\circ}$. Moreover, PSPMA surfaces are negatively charged; negatively charged fibroblasts resisted cell attachment. Other research has similarly been shown to lower the water contact angles of poly(tetrafluoroethylene) (PTFE) from $108.5^{\circ}$ to $58.7^{\circ}$ [21, 22] or $46.5^{\circ}$ [23] poly(dimethylsiloxane) (PDMS) from $104.4^{\circ}$ to $65.5^{\circ}[21,22]$ and titanium from $68.6^{\circ}$ to $44.3^{\circ}[21,24]$. This hydrophilicity-conferring property and propensity for modification make PD an ideal biomaterial and as such has been considered for tissue engineering applications and implants [9]. PD's antibacterial properties appear to be due to the fact that monomeric dopamine can be cytotoxic, but polymeric PD is devoid of such activity. Hong et al. [2] found that some of the dopamine in the PD remains unpolymerized, but trapped within the PD matrix and can be released over time to provide an antibacterial effect.

The generation of PD is typically through the simple process of self-polymerisation/auto-oxidation of dopamine in a slightly basic environment [25]. The final product can be applied as a coating on a wide range of surfaces including metals, polymers and glasses [21]. The substrate can be removed after functionalisation if desired, with hydrofluoric acid or ammonium fluoride $[8,26]$, for example, to produce a nanosheet [8]. Despite the ease of its production, the structure of PD remains elusive, though Hong et al. [2] report that it is the result of both physical selfassembly and covalent oxidative polymerisation of dopamine and 5,6-dihydroxyindole (the oxidative product of dopamine). The self-polymerisation method creates small spherical particles of PD with a range of sizes (100-500 nm) which aggregate on surfaces into larger particles $(0.5-5 \mu \mathrm{m})$ to provide thicker films, with higher self-polymerisation temperatures providing smaller particles and thinner films [27, 28]. The rate of polymerisation/oxidation has also found to be dependent on the dopamine concentration, oxygen concentration and $\mathrm{pH}$ [27].

Despite previous experiments with PD-coated particles and surfaces, the adhesive forces between PD and various surfaces have yet to be quantified. This research investigates the adhesion to protein-, polymer- and PD-coated surfaces via atomic force microscopy. Serum albumin, mucin and trypsin were used as model proteins.

Mucins are heavily glycosylated proteins forming mucous layers found throughout the digestive and pulmonary systems forming a protective physical barrier for mucosal surfaces. Though experiments have been performed with PD and mucin (MUC1) antibodies [29], to the authors' knowledge no other PD mucin adhesion experiments have been performed. However, it was expected that adhesion to mucin would be low since a PEG-PD coating was found to reduce mucin adsorption even though the effect of PD alone was not significant; [18] and low mucin-mucin adhesive forces were seen by Berry et al. [30]. This agrees with Dague et al. [31], who observed that Lactococcus lactis adhesion decreased after mucin adsorption. PD has been considered for use in oral formulations which benefit from the effect of $\mathrm{pH}$ on its release of encapsulated drugs [32], so it is of interest to investigate its interactions with mucin.

Albumin is the principal blood plasma protein and plays a role in maintenance of osmotic pressure and transport of critical biomolecules, such as hormones [33]. Albumin is therefore relevant to understand interactions with vascular stent devices. ZelaskoLeon et al. [29] have previously immobilised MUC1 antibodies and albumin to gold nanorods via a PD coating which could suggest that BSA-PD adhesion, or at least adsorption, does occur. Human serum albumin has been observed to reduce the size of $\mathrm{PD}$ aggregates formed on a surface [34].

Trypsin is a proteolytic enzyme found in vertebrates' digestive systems so is relevant for devices such as diagnostic intestinal imaging cameras and orally administered drug formulations. Koutsopoulos et al. [35] investigated trypsin adsorption to polystyrene (PS) and to silica and found that its affinity for hydrophobic PS was greater than for hydrophilic 
silica. Since PD has exhibited hydrophilic tendencies, it may again be expected that PD trypsin adhesion may be low. Despite this, it is not clear what the difference will be, since the unfunctionalised silicon nitride probe used as the control is also hydrophilic with a water contact angle of $32 \pm 12^{\circ}$ [36]. Therefore, it is important to understand the interactions of PD with synthetic materials, such as polymers used in biomedical applications.

Poly(E-caprolactone) (PCL), poly (L-lactic acid) (PLLA) and poly (2-hydroxyethylmethacrylate) (PHEMA) were used as test polymers because they have applications as biomaterials due to their corrosion resistance, cytocompatibility and degradability that allows drug release [37,38]. PCL fibres have been coated with PD and investigated for use as bone tissue scaffolds [39], and 3D-printed scaffolds of PCL have been coated with PD resulting in an improvement in cell density versus control [17]. PLLA can be used for tendon repair [40], as a coating for stents [41] or made into scaffolds and coated with PD which improved adhesion and cell proliferation [7,42]. PHEMA has uses as a tissue engineering scaffold, sometimes as a hydrogel [38], and for the immobilisation of proteins [43].

In this investigation, the adhesive forces between PD-, protein- or polymer-coated surfaces and bare silicon nitride or polydopamine-functionalised AFM probes are measured. Surfaces are also characterised with AFM for roughness $\left(R_{\mathrm{a}}\right)$ and morphology, with contact angle goniometry (CAG) for hydrophobicity and surface energy and with RAMAN and FTIR for spectroscopic evaluation.

\section{Materials and methods}

\section{Materials}

Dopamine hydrochloride (H8502) was purchased from Sigma (Germany), and Tris (hydroxymethyl) aminomethane (Tris; $\geq 99.8 \%$ ) from Sigma Aldrich (USA). Porcine gastric mucin type II (PGM; Sigma M2378), bovine serum albumin (BSA; Sigma A7906), trypsin (Sigma T4549), diiodomethane (DIM; 99\%) and phosphate-buffered saline (PBS; pH 7.4) tablets were purchased from Sigma (USA). Ethylene glycol (EG; 99.8\%) was purchased from Sigma Aldrich (UK), and dichloromethane (DCM), N-dimethylformamide (DMF) and 3-aminopropyltriethoxysilane (APTES; 99\%) were all purchased from Sigma Aldrich (China). PLLA $\left(\mathrm{M}_{\mathrm{W}} \sim 55000 \mathrm{~g} \mathrm{~mol}^{-1}\right)$ was purchased from Aldrich (Germany), and PCL $\left(\mathrm{M}_{\mathrm{W}} 14000 \mathrm{~g} \mathrm{~mol}^{-1}\right)$ and PHEMA $\left(\mathrm{M}_{\mathrm{V}} 20000 \mathrm{~g} \mathrm{~mol}^{-1}\right)$ were purchased from Aldrich (USA).

\section{Preparation of substrates and AFM cantilevers}

PD was grafted onto surfaces by immersion in a basic ( $\mathrm{pH}$ 8.5) solution of $10 \mathrm{mM}$ Tris and $2 \mathrm{~g} \mathrm{~L}^{-1}$ (10.5 $\mathrm{mM}$ ) dopamine hydrochloride in DW overnight ( $\sim 18 \mathrm{~h}$ ) as per previous groups (Fig. 1) [25, 44-46]. AFM probes were APTES-functionalised in a manner equivalent to Hong et al. [47] and Lyubchenko et al. [48], to act as a primer to further functionalisation; the probes were left in APTES vapour for at least $30 \mathrm{~min}$. Though PD is a good coating material for surfaces, APTES may ensure that it stays attached throughout the experiment. The probes were removed from the vapour and then washed with DW. Thereafter, the PD functionalisation was as above.

Drop casting was used to coat silicon wafer (SW) with polymers other than PD. Solutions were made with a polymer concentration of $2 \% \mathrm{w} / \mathrm{v}$. PLLA and PCL were dissolved in DCM, while PHEMA was dissolved in DMF. Polymer solution was added to squares of SW $\left(10 \times 10 \mathrm{~mm}^{2}\right)$. Solvent was allowed to evaporate in a fume cupboard until dry and samples were stored in a desiccator until measurement. Drop casting was also used to coat SW with protein.
Table 1 Surface

characterisation: contact angles $(n \geq 6)$ and surface energies by $\mathrm{CAG}$, and roughness $\left(R_{\mathrm{a}}\right)$ by AFM

\begin{tabular}{|c|c|c|c|c|c|c|c|c|}
\hline \multirow[b]{2}{*}{ Surface } & \multicolumn{3}{|c|}{ Contact Angle $\left(\theta,{ }^{\circ}\right)$} & \multicolumn{4}{|c|}{ Surface energy $\left(\mathrm{mJ} \mathrm{m}^{-2}\right)$} & \multirow{2}{*}{$\begin{array}{l}\text { Roughness (nm) } \\
R_{\mathrm{a}}\end{array}$} \\
\hline & DW & EG & DIM & $\gamma_{\mathrm{s}}^{+}$ & $\gamma_{\mathrm{s}}^{-}$ & $\gamma_{\mathrm{s}}^{\mathrm{LW}}$ & $\gamma_{\mathrm{s}}$ & \\
\hline PHEMA & $52.7 \pm 1.9$ & $64.5 \pm 2.8$ & $32.3 \pm 1.2$ & 2.53 & 50.21 & 43.24 & 65.77 & $4.3 \pm 4.1$ \\
\hline PLLA & $94.8 \pm 7.3$ & $70.5 \pm 1.9$ & $56.4 \pm 2.1$ & 0 & 2.12 & 30.65 & 30.72 & $41.7 \pm 14.8$ \\
\hline PCL & $93.1 \pm 2.5$ & $65.3 \pm 2.5$ & $32.9 \pm 1.2$ & 0.18 & 1.41 & 42.98 & 43.98 & $39.4 \pm 4.7$ \\
\hline PD & $16.8 \pm 4.0$ & $20.1 \pm 1.9$ & $54.6 \pm 4.6$ & 0.51 & 67.17 & 31.68 & 43.33 & $9.8 \pm 0.5$ \\
\hline Mica & $<10$ & $33.8 \pm 2.5$ & $37.2 \pm 1.8$ & 0.16 & 77.12 & 47.95 & 47.91 & $0.4 \pm 0.2$ \\
\hline
\end{tabular}




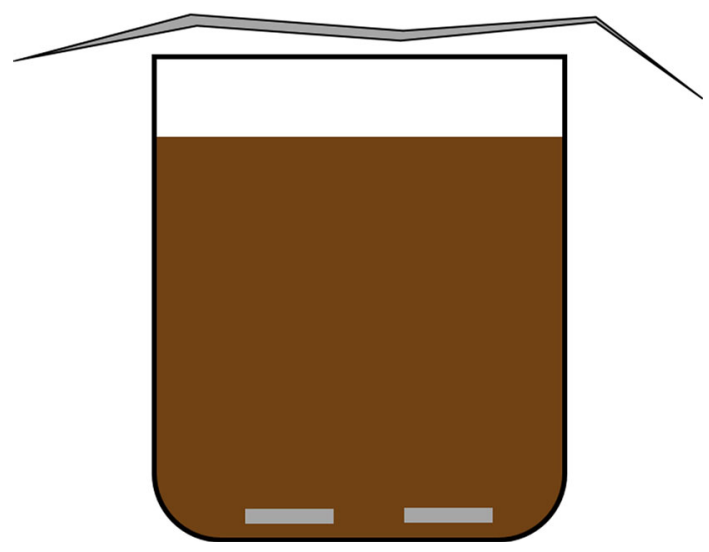

Figure 1 Production of PD-coated SW. Squares of SW were left in solution overnight and loosely covered with foil to keep dust out but allow oxygen in.

BSA and PGM were each dissolved in PBS to $3.0 \mathrm{mg} \mathrm{mL}^{-1}$. After vortexing, a maximal volume (as above; up to $300 \mu \mathrm{L} \mathrm{cm}^{-2}$ ) was placed on a square of SW $(10 \mathrm{~mm} \times 10 \mathrm{~mm})$. This was allowed to dry in a fume cupboard overnight. A large range of concentrations have been used previously in our laboratory in order to produce protein films, and this combination of concentration and volume was found to be sufficient to leave a visible deposit on the surfaces.

\section{Contact angle and surface energy measurements}

To probe liquid-surface interactions, contact angles $\left(\theta\right.$ at $20^{\circ} \mathrm{C}$ ) of small drops (typically $2-10 \mu \mathrm{L} ; 2-3$ drops per substrate and 2-3 substrates per sample) of deionised water (DW; Millipore, $18.2 \mathrm{M} \Omega \mathrm{cm}$; surface tension $\gamma_{\mathrm{L}}=73.5 \mathrm{mN} \mathrm{m}^{-1}$ at $15{ }^{\circ} \mathrm{C}$ [49]), DIM (>99\%; $\gamma_{\mathrm{L}}=50.8 \mathrm{mN} \mathrm{m}^{-1}$ at $20^{\circ} \mathrm{C}$ [50]) and EG (>99\%; $\gamma_{\mathrm{L}}=47.7 \mathrm{mN} \mathrm{m}^{-1}$ at $20^{\circ} \mathrm{C}$ [50]) placed on horizontal substrates were measured using a Krüss DSA30B contact angle goniometer (CAG) with Krüss ADVANCE drop analysis software. Static contact angles $\left(\theta ; \pm 0.1^{\circ}\right)$ were obtained for both left and right contact angles $5 \mathrm{~s}$ after placement of the drop. Surface energies of substrates $\left(\gamma_{\mathrm{s}}\right)$ were calculated from the contact angles and the interfacial energies of the three probe liquids using the Good and Oss [51] three-liquid formula (Eqs. 1, 2 and 3), using an inhouse Visual Basic program as per Lamprou et al. [52]. Contact angle measurements were performed after AFM or on alternate surfaces in order to ensure that the drops dip did not affect the surface morphology. Because mica's water contact angle proved too low to accurately measure on our apparatus, a value of $10^{\circ}$ was chosen. The value has previously been shown to be $<10^{\circ}$ [53].

$$
\begin{aligned}
& \gamma_{\mathrm{S}}=\gamma_{\mathrm{S}}^{\mathrm{LW}}+\gamma_{\mathrm{S}}^{\mathrm{AB}}=\gamma_{\mathrm{S}}^{\mathrm{LW}}+2\left(\gamma_{\mathrm{S}}^{+} \gamma_{\mathrm{S}}^{-}\right)^{1 / 2} \\
& \gamma_{\mathrm{L}}=\gamma_{\mathrm{L}}^{\mathrm{LW}}+\gamma_{\mathrm{L}}^{\mathrm{AB}}=\gamma_{\mathrm{L}}^{\mathrm{LW}}+2\left(\gamma_{\mathrm{L}}^{+} \gamma_{\mathrm{L}}^{-}\right)^{1 / 2} \\
& \gamma_{\mathrm{L}}(1+\cos \theta)=2\left[\left(\gamma_{\mathrm{S}}^{\mathrm{LW}} \gamma_{\mathrm{L}}^{\mathrm{LW}}\right)^{1 / 2}+\left(\gamma_{\mathrm{S}}^{+} \gamma_{\mathrm{L}}^{-}\right)^{1 / 2}+\left(\gamma_{\mathrm{S}}^{-} \gamma_{\mathrm{L}}^{+}\right)^{1 / 2}\right]
\end{aligned}
$$

where superscripts denote components of surface energy, LW Lifshitz-van der Waals, AB acid-base, $\gamma^{+}$ Lewis acid and $\gamma^{-}$Lewis base.

\section{Atomic force microscopy}

A Bruker Multimode 8 atomic force microscope with Nanoscope V controller was used for the AFM measurements. Measurements were made in air under ambient conditions. Spring constants and resonant frequencies for the cantilevers were determined with the thermal noise method at the start of each experiment. Force-distance plots were obtained at random locations on the sample using a V-shaped ScanAsyst air probe (nominal spring constant $0.4 \mathrm{~N} \mathrm{~m}^{-1}$; nominal resonant frequency $70 \mathrm{kHz}$; nominal length $600 \mathrm{~nm}$ ) in force-volume which performs ramps in a grid. Force curves were selected at random from a $32 \times 32$ array. Adhesion forces $\left(\mathrm{F}_{\mathrm{a}} ; \mathrm{n}=80-90\right)$ were extracted from the force curves (example given in Supplementary Information 1) using a on house prepare Python script, previously used in Mallinson et al. [54]. Forces were then normalised for tip radius by dividing the force by tip radius proportional to Sugawara et al.'s [55] correction shown in Eq. 4.

$A=4 \pi R T$,

where $A$ is corrected adhesion, $R$ tip radius and $T$ medium surface tension.

The tip radius $(R)$ was determined by scanning (scan size $5 \mu \mathrm{m}$, scan rate $1 \mathrm{~Hz}$ ) an etched silicon surface (PA01, MikroMasch, San Jose, CA, USA) in peak force-quantitative nanomechanical mapping (PF-QNM) mode followed by using the tip qualification function within Nanoscope Analysis. Surface morphology was imaged in PF-QNM mode. The surface roughness $\left(R_{\mathrm{a}}\right)$ of each substrate was determined by using Nanoscope Analysis' algorithm to 
analyse several scans of the surface from different locations.

\section{Circular dichroism}

Circular dichroism (CD) was used to probe the secondary structure of the proteins and attempt to identify any secondary structure in the PD. Spectra were read in the wavelength range of 190-280 nm with a Chirascan Plus spectrophotometer (Applied Photophysics). A step size of $1 \mathrm{~nm}$, bandwidth of $1 \mathrm{~nm}$ and reading time of $1 \mathrm{~s}$ per point were chosen. The samples were placed in a quartz cuvette (Hellma) with a path length of $0.1 \mathrm{~mm}$. DW (Millipore) was used as the background. Whole PD, the product of the above process, and the same solution passed through a $0.2-\mu \mathrm{m}$ syringe filter such that no particles were visible were used as samples. Three spectra were recorded for each sample, averaged, smoothed and the background subtracted. Data were processed with Chirascan Viewer and Microsoft Excel.

\section{Spectroscopic analysis}

Fourier-transform infrared spectroscopy (FTIR) spectra were taken for dopamine hydrochloride and PD. PD, as prepared above, was centrifuged at $2000 \mathrm{rpm}$ for $5 \mathrm{~min}$, and then supernatant was removed. The pellet was spread on a glass slide and allowed to dry before measurements. Spectra were recorded with a Bruker Tensor II FTIR spectrometer in the wavenumber range $400-4000 \mathrm{~cm}^{-1}$. Each sample spectrum was made of 16 scans.

Raman spectra were taken for dopamine hydrochloride and PD, prepared as for FTIR, using a Horiba Scientific XPloRA Plus Raman microscope calibrated with SW. Measurements were taken with a green $(532 \mathrm{~nm})$ laser in the wavenumber range of $50-3600 \mathrm{~cm}^{-1}$ with a grating of 1800 gratings $\mathrm{mm}^{-1}$, a $100 \mu \mathrm{m}$ slit and $\mathrm{a} \times 10$ objective lens. Spectra were recorded at three locations per sample and the backgrounds removed.

\section{Statistics}

Data were processed with Microsoft Excel 2016 and Minitab 17. Pairwise differences in adhesion results were analysed with a series of 2-sample $t$ test with a significance level of 0.05 .

\section{Results and discussion}

\section{Surface characterisation}

After PD functionalisation, surfaces were visibly different, displaying a black-sepia tint that remained even after washing with DW. The PD layer could be expected to be approximately $50 \mathrm{~nm}$ thick which is the approximate thickness attained after immersion for $18 \mathrm{~h}$ seemingly regardless of substrate according to Liu et al. [12] and Lynge et al. [56]. The water contact angle (Table 1) for PD-coated SW was low $\left(16.8 \pm 4.0^{\circ}\right)$, indicating high hydrophilicity and showed good similarity with Perikamana et al.'s [21] values for PD-coated PLLA-hemp composites $\left(16.9 \pm 1.6^{\circ}\right)$. This could be due to the coating being powder like. However, an even more extreme example was seen by $\mathrm{Ku}$ et al. [6] who observed a water contact angle of $0^{\circ}$, i.e. complete wetting, for PD-functionalised poly (lactic-co-glycolic acid) (PLGA) nanofibres.

The water contact angle for PCL was higher than recorded by other groups-93.1 $\pm 2.5^{\circ}$ compared to $74^{\circ}$ [57] or $82.7 \pm 3.2^{\circ}$ [58] —as was the water contact angle for PHEMA $-52.7 \pm 1.9^{\circ}$ compared to $\sim 20^{\circ}$ [59] - though the PLLA water contact angle was in agreement with other recorded values-94.8 $\pm 7.3^{\circ}$ compared with $98.0 \pm 2.3^{\circ}$ [60]. The difference may be due to topographical differences since the dimpled textures (Fig. 2a-c) can increase hydrophobicity though this does not appear to have had the same effect upon PLLA's water contact angle.

\section{Morphology}

The images in Fig. 2 are shown at scales that best display the features observed. The polymer films (Fig. 2a-c) show flat but featured surfaces. Dimples can be seen on the films which are likely from condensed water droplets acting as a template for the polymer as it was cast by the evaporating solvent. This is similar to the process for breath figure array formation-where water droplets condensing as the solvent evaporates act as a template for the polymer as it is cast-but here the pores lack order, likely due to the dry environment in which they were cast. With a similar appearance to the PD previously observed via AFM [5], the image of deposited PD (Fig. 2d) shows a majority of small particles (100-250 nm) with some larger aggregates (350-550 nm) which fall in 

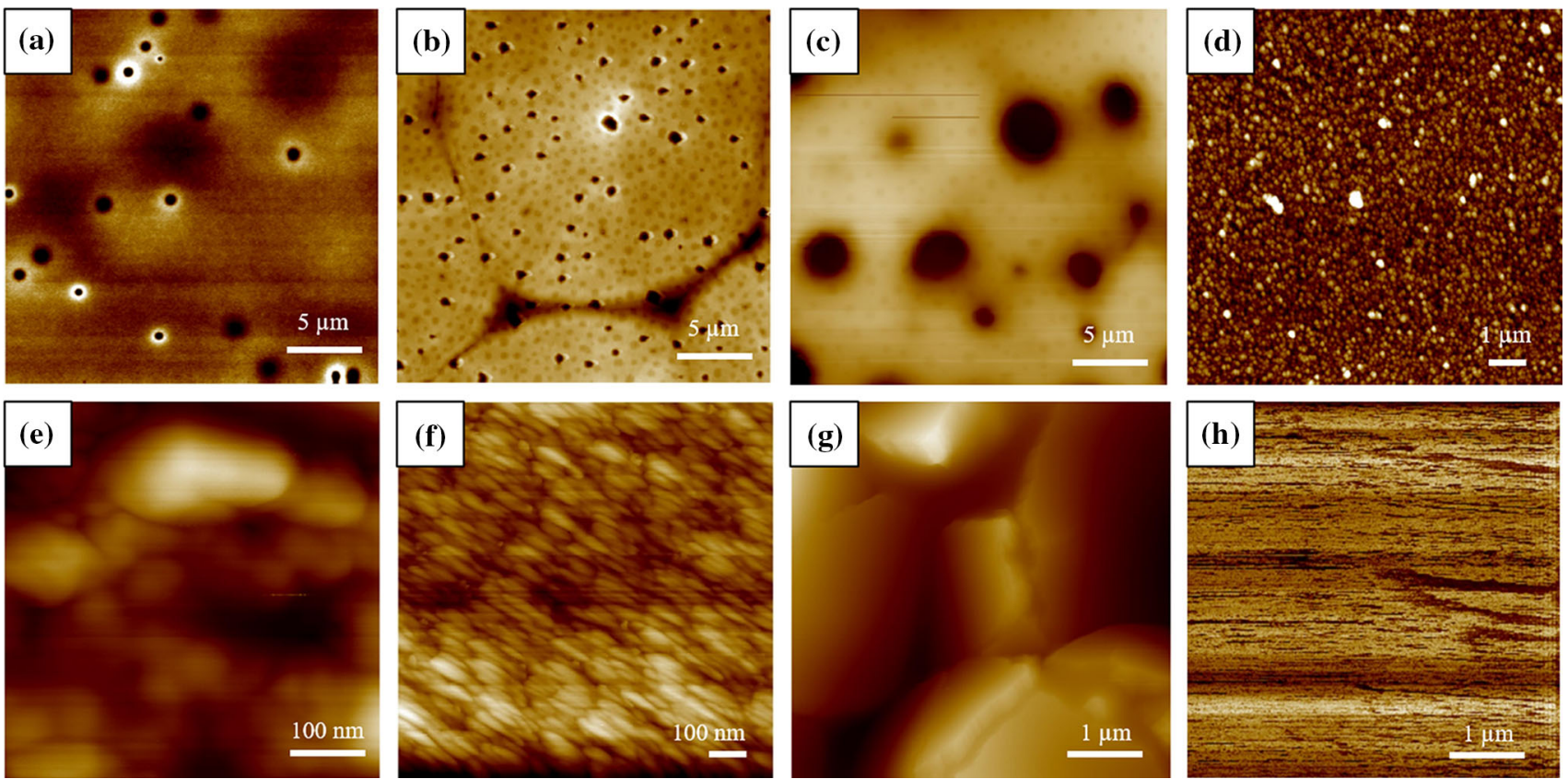

Figure 2 Morphology of surfaces by AFM: a PHEMA; b PCL; c PLLA; $\mathbf{d}$ PD; e PGM; $\mathbf{f}$ BSA; $\mathbf{g}$ trypsin; $\mathbf{h}$ mica.

the range of sizes observed by others [5, 27, 28]. This sample was found to be smoother $\left(R_{\mathrm{a}} 9.8 \pm 0.5 \mathrm{~nm}\right)$ than reported values from $\mathrm{Bi}$ et al. [23]. $\left(R_{\mathrm{a}}\right.$
$35.8 \pm 2.1 \mathrm{~nm}$ ) though the substrate of $\mathrm{SW}$ in our studies was smoother $\left(R_{\mathrm{a}} 0.15 \pm 0.04 \mathrm{~nm}\right.$ [61] $)$ than the previously reported PTFE substrate

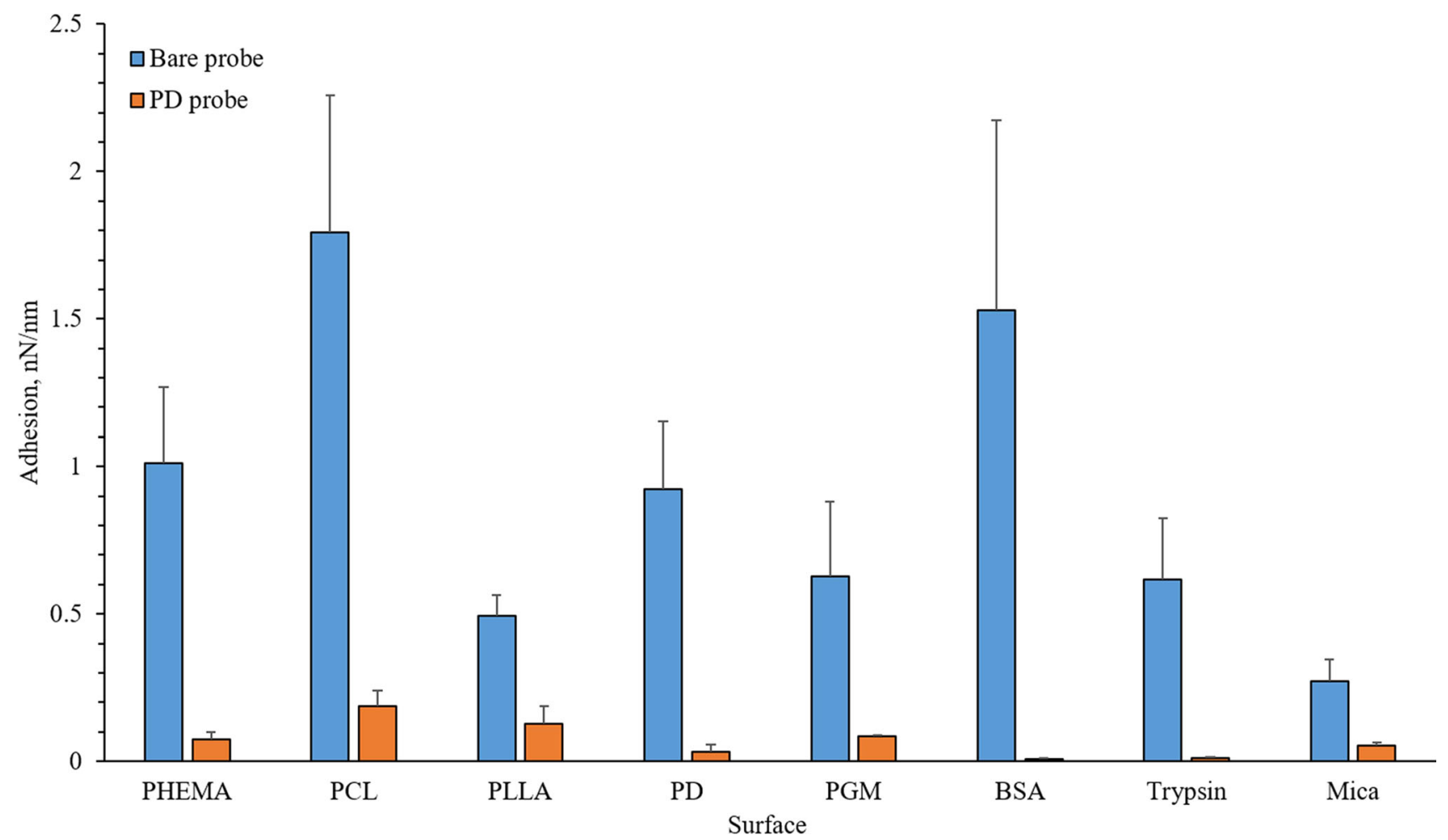

Figure 3 Mean adhesion $( \pm S D)$ to different surfaces with bare or PD-functionalised AFM probes adjusted for tip radius. All pairs are significantly different $(P<0.001)$. 


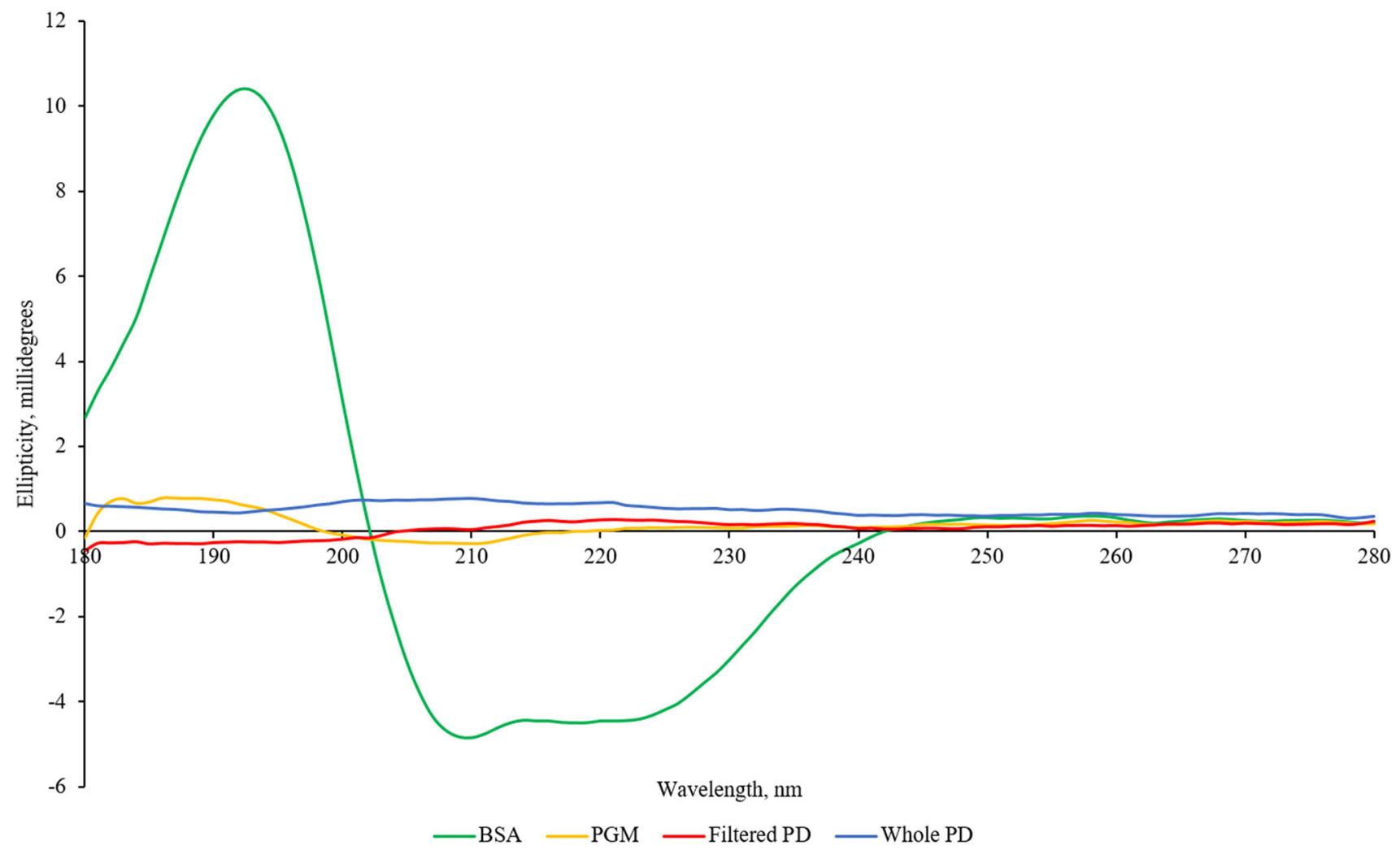

Figure 4 Circular dichroism spectra of PD, BSA and PGM.

$(24.2 \pm 1.3 \mathrm{~nm})$ [23]. The dried protein films (Fig. 2eg) show textured surfaces with PGM (e) and BSA (f) having rounder features than the relatively 'mountainous' trypsin (g). Mica (Fig. 2h), on the other hand, is very flat-the z-axis was on the order of nanometres.

\section{Adhesion}

When the forces are adjusted to the force tip radius, all adhesive forces recorded with a PD-functionalised probe are significantly $(P<0.001)$ lower than with a bare, silicon nitride probe (Fig. 3). Since it has been found that PD supports cell growth [5], it might be expected that the proteins would experience more adhesion though the opposite appears to be true even when the unadjusted values are considered (Supplementary Information 2) except for mucin.

The low adhesion observed with the PD-functionalised probes appears contradictory to the ease that PD can functionalise surfaces, as enabled by the displayed catechol, imine and amine groups [32]. The apparent low adhesion to protein films suggests that it may be ideal as a biomaterial or biomaterial coating by minimising interactions with proteins. However, these experiments took place in a dried environment and a solvent (e.g. PBS or serum) might have an effect on the adhesion and thus on the force-distance plots that have been measured. Therefore, adhesion forces might change in wet environment.

\section{Circular dichroism}

Due to the structure PD assumes when it self-polymerises [2] it is expected that it would be unlikely to display peaks that are synonymous with protein secondary structure noticeable by $\mathrm{CD}$ and indeed it does not since it is not a polypeptide. Although there do not appear to be any spectra of PD in the literature, Zelasko-Leon et al. [29] show a spectrum of PDfunctionalised gold nanorods which exhibits no positive or negative maxima. The filtered PD product had a sepia colour, but had no visible particles. Neither this filtered PD product nor the unfiltered, whole PD product gave any discernible signal above the background (Fig. 4).

The crystal structure of BSA (Protein Data Bank (PDB) 4F5S) [62] shows an abundance of alpha 
helices. The negative and positive maxima at $208 \mathrm{~nm}$ and 193 nm, respectively, seen in Fig. 4 are in very good agreement with what is expected for alpha helices [63]. Alpha helices also show negative ellipticity at $222 \mathrm{~nm}$ which may be present in the spectrum. This suggests that the protein retained its expected structure when reconstituted.

Mucins tend to have very little beta secondary structure and even less alpha secondary structure and are instead mostly random coil [64]. This could be reflected by the very weak ellipticity that is barely above the background.

Trypsin contains some alpha helices and beta-pleated sheets (RCSB entries 5GXP [65] and 5JYI [66]). The spectrum reported in Supplementary Information 3 agrees with this by the positive maximum at $193 \mathrm{~nm}$ [63]. It also shows negative maxima at $197 \mathrm{~nm}$ which corresponds to random coil structures [67] as well as at 202 and $204 \mathrm{~nm}$, but these do not appear to correspond to any obvious secondary structure. There is also a local negative minimum at $208 \mathrm{~nm}$ which may be due to alpha helices.

\section{Spectroscopic analysis}

The FTIR spectrum (Fig. 5) for dopamine hydrochloride is consistent with spectra gathered by other groups [68]. A peak that is common for both dopamine hydrochloride and PD near $1500 \mathrm{~cm}^{-1}$ may be attributed to aromatic regions that are common in both structures. The spectrum for the PD product appears to resemble the spectrum that would be achieved by overlaying the spectra for dopamine hydrochloride and Tris base, and also shows similarity to spectra obtained by Iqbal et al. [4] for PD with the $1200-1500 \mathrm{~cm}^{-1}$ region being assigned to $C-$ $\mathrm{C}, \mathrm{C}-\mathrm{O}$ and $\mathrm{C}-\mathrm{N}$, and the $3000 \mathrm{~cm}^{-1}$ region assigned to $\mathrm{C}, \mathrm{N}, \mathrm{O}$ and $3500 \mathrm{~cm}^{-1}$ to primary amine stretching which is supportive of PD. There is also similarity to Mei et al.'s [18] spectrum with a common peak near $1600 \mathrm{~cm}^{-1}$ indicative of aromatic rings. There is further similarity to spectra obtained Iqbal et al. [69] for PD-coated nanoparticles and good similarity to the spectrum obtained by Steeves et al. [5] for PD with nanoporous titanium.

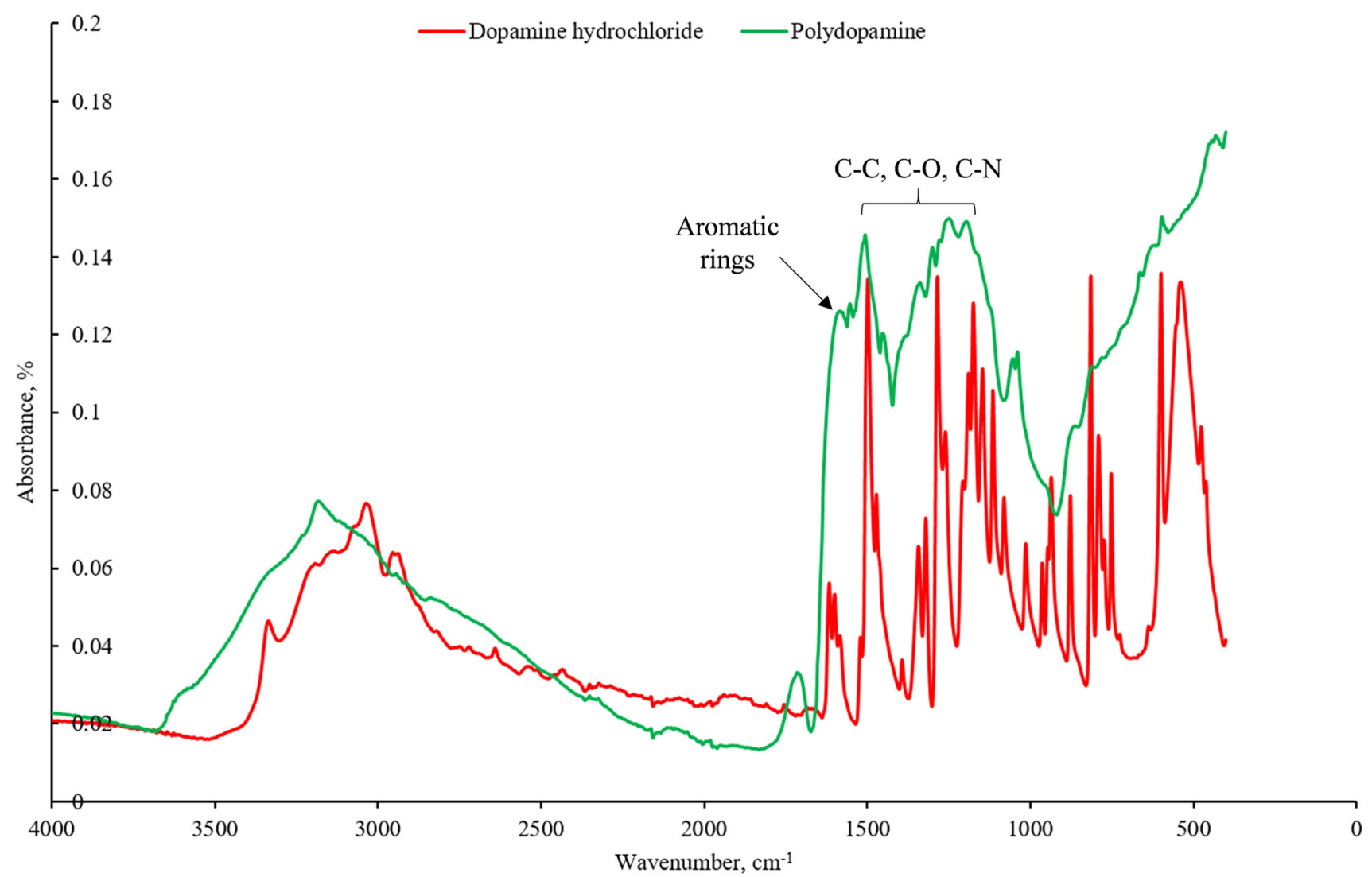

Figure 5 FTIR spectra of dopamine hydrochloride and the PD product. 


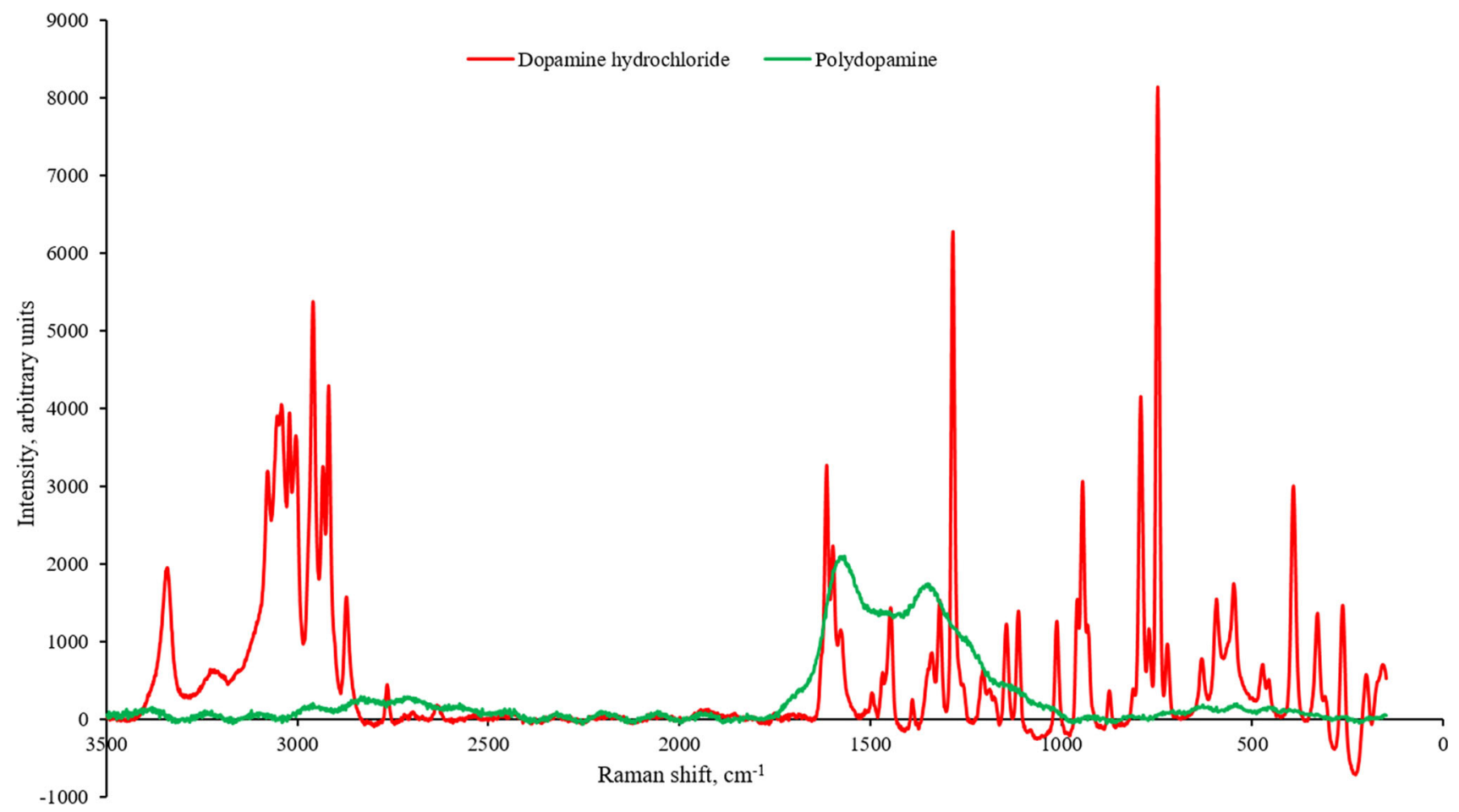

Figure 6 Raman spectra of dopamine hydrochloride and PD.

Raman spectra were consistent between scans in different locations for the same samples (data not shown); however, the spectra (Fig. 6) for each material are different. The dopamine hydrochloride spectra show peaks typical of aliphatic chains $\left(600-1300 \mathrm{~cm}^{-1}\right)$, while the peaks (not shown) in the low wavelength range $\left(10-200 \mathrm{~cm}^{-1}\right)$ were suggestive of crystallinity. The dopamine hydrochloride spectrum matched that of the supplier [70]. The Raman spectra for PD show similarities to those obtained previously by other groups such as Ma et al. [71], Steeves et al. [5] for PD with nanoporous titanium, Lee et al. [9] for coated titanium and Qiu et al. [72] for $\mathrm{MnCO}_{3}$ with PD which show bands at 1350 and $1580 \mathrm{~cm}^{-1}$ which, as for dopamine hydrochloride, are suggestive of aliphatic and aromatic components $[6,71]$.

\section{Conclusion}

PD has been considered as a biomaterial due to its ease of application and promotion of cell growth. The product was found to resemble the PD produced by previous groups. By atomic force microscopy, PDfunctionalised probes to protein films and polymer films were significantly lower than with an unfunctionalised silicon nitride probe, suggesting that a PD could be a useful coating for reducing interaction with protein that may otherwise lead to fouling. This supports the trend towards using PD as a coating for biomedical devices.

\section{Acknowledgements}

The authors would like to thank the UK Engineering \& Physical Sciences Research Council (EPSRC) Doctoral Training Partnership, University of Strathclyde (EPSRC Grant Ref. EP/K503289/1) for the studentship awarded to David Mallinson. The authors would also like to thank the EPSRC Centre in Continuous Manufacturing and Crystallisation (CMAC) for access to specialised instruments.

Electronic supplementary material: The online version of this article (https://doi.org/10.1007/ s10853-017-1806-y) contains supplementary material, which is available to authorized users.

Open Access This article is distributed under the terms of the Creative Commons Attribution 4.0 
International License (http://creativecommons.org/ licenses/by/4.0/), which permits unrestricted use, distribution, and reproduction in any medium, provided you give appropriate credit to the original author(s) and the source, provide a link to the Creative Commons license, and indicate if changes were made.

\section{References}

[1] Smith JR, Lamprou DA (2014) Polymer coatings for biomedical applications: a review. Trans IMF 92:9-19

[2] Hong S, Na YS, Choi S, Song IT, Kim WY, Lee H (2012) Non-covalent self-assembly and covalent polymerization cocontribute to polydopamine formation. Adv Funct Mater 22:4711-4717

[3] Su L, Yu Y, Zhao YS, Liang F, Zhang XJ (2016) Strong antibacterial polydopamine coatings prepared by a shakingassisted method. Sci Rep 6:24420

[4] Iqbal Z, Lai EPC, Avis TJ (2012) Antimicrobial effect of polydopamine coating on Escherichia coli. J Mater Chem 22:21608-21612

[5] Steeves AJ, Atwal A, Schock SC, Variola F (2016) Evaluation of the direct effects of poly(dopamine) on the in vitro response of human osteoblastic cells. J Mater Chem B 4:3145-3156

[6] Ku SH, Park CB (2010) Human endothelial cell growth on mussel-inspired nanofiber scaffold for vascular tissue engineering. Biomaterials 31:9431-9437

[7] Kao CT, Lin CC, Chen YW, Yeh CH, Fang HY, Shie MY (2015) Poly(dopamine) coating of 3D printed poly(lactic acid) scaffolds for bone tissue engineering. Mater Sci Eng C Mater Biol Appl 56:165-173

[8] Hafner D, Ziegler L, Ichwan M, Zhang T, Schneider M, Schiffmann M, Thomas C, Hinrichs K, Jordan R, Amin I (2016) Mussel-inspired polymer carpets: direct photografting of polymer brushes on polydopamine nanosheets for controlled cell adhesion. Adv Mater 28:1489-1494

[9] Lee JJ, Park IS, Shin GS, Lyu SK, Ahn SG, Bae TS, Lee MH (2014) Effects of polydopamine coating on the bioactivity of titanium for dental implants. Int $\mathrm{J}$ Precis Eng Manuf 15:1647-1655

[10] Meeker DG, Jenkins SV, Miller EK, Beenken KE, Loughran AJ, Powless A, Muldoon TJ, Galanzha EI, Zharov VP, Smeltzer MS, Chen J (2016) Synergistic photothermal and antibiotic killing of biofilm-associated Staphylococcus aureus using targeted antibiotic-loaded gold nanoconstructs. ACS Infect Dis 2:241-250
[11] He S, Zhou P, Wang L, Xiong X, Zhang Y, Deng Y (2014) Antibiotic-decorated titanium with enhanced antibacterial activity through adhesive polydopamine for dental/bone implant. J R Soc Interface 11:20140169

[12] Liu Y, Ai K, Lu L (2014) Polydopamine and its derivative materials: synthesis and promising applications in energy, environmental, and biomedical fields. Chem Rev 114:5057-5115

[13] Knorr DB, Tran NT, Gaskell KJ, Orlicki JA, Woicik JC, Jaye C, Fischer DA, Lenhart JL (2016) Synthesis and characterization of aminopropyltriethoxysilane-polydopamine coatings. Langmuir 32(17):4370-4381

[14] Tapsir Z, Saidin S (2016) Synthesis and characterization of collagen-hydroxyapatite immobilized on polydopamine grafted stainless steel. Surf Coat Technol 285:11-16

[15] Lim K, Chua RR, Bow H, Tambyah PA, Hadinoto K, Leong SS (2015) Development of a catheter functionalized by a polydopamine peptide coating with antimicrobial and antibiofilm properties. Acta Biomater 15:127-138

[16] Chuah YJ, Koh YT, Lim K, Menon NV, Wu Y, Kang Y (2015) Simple surface engineering of polydimethylsiloxane with polydopamine for stabilized mesenchymal stem cell adhesion and multipotency. Sci Rep 5:18162

[17] Jo S, Kang SM, Park SA, Kim WD, Kwak J, Lee H (2013) Enhanced adhesion of preosteoblasts inside 3D PCL scaffolds by polydopamine coating and mineralization. Macromol Biosci 13:1389-1395

[18] Mei ML, Li Q, Chu CH (2016) Inhibition of cariogenic plaque formation on root surface with polydopamine-induced-polyethylene glycol coating. Materials (Basel) 9:414

[19] Im KM, Kim T, Jeon J (2017) Metal-chelation-assisted deposition of polydopamine on human hair: a ready-to-use eumelanin-based hair dyeing methodology. ACS Biomater Sci Eng 3:628-636

[20] Zhong S, Luo RF, Wang X, Tang LL, Wu J, Wang J, Huang RB, Sun H, Huang N (2014) Effects of polydopamine functionalized titanium dioxide nanotubes on endothelial cell and smooth muscle cell. Colloids Surf B 116:553-560

[21] Madhurakkat Perikamana SK, Lee J, Lee YB, Shin YM, Lee EJ, Mikos AG, Shin H (2015) Materials from mussel-inspired chemistry for cell and tissue engineering applications. Biomacromol 16:2541-2555

[22] Ku SH, Ryu J, Hong SK, Lee H, Park CB (2010) General functionalization route for cell adhesion on non-wetting surfaces. Biomaterials 31:2535-2541

[23] Bi Y, Zhou H, Jia H, Wei P (2017) Polydopamine-mediated preparation of an enzyme-immobilized microreactor for the rapid production of wax ester. RSC Adv 7:12283-12291

[24] Nijhuis AWG, van den Beucken JJJP, Jansen JA, Leeuwenburgh SCG (2014) In vitro response to alkaline 
phosphatase coatings immobilized onto titanium implants using electrospray deposition or polydopamine-assisted deposition. J Biomed Mater Res A 102:1102-1109

[25] Lee H, Dellatore SM, Miller WM, Messersmith PB (2007) Mussel-inspired surface chemistry for multifunctional coatings. Science (80-) 318:426-430

[26] Postma A, Yan Y, Wang Y, Zelikin AN, Tjipto E, Caruso F (2009) Self-polymerization of dopamine as a versatile and robust technique to prepare polymer capsules. Chem Mater Am Chem Soc 21:3042-3044

[27] Ju K-Y, Lee Y, Lee S, Park SB, Lee J-K (2011) Bioinspired polymerization of dopamine to generate melanin-like nanoparticles having an excellent free-radical-scavenging property. Biomacromol 12:625-632

[28] Jiang L, Jin GC, Kang J, Yu LM, Yoon W, Lim M, Par KI, Lee M, Jin DC (2014) Surface characteristics of musselinspired polydopamine coating on titanium substrates. J Wuhan Univ Technol Sci Ed 29:197-200

[29] Zelasko-Leon DC, Fuentes CM, Messersmith PB (2015) MUC1-targeted cancer cell photothermal ablation using bioinspired gold nanorods. PLoS ONE 10:e0128756

[30] Berry M, McMaster TJ, Corfield AP, Miles MJ (2001) Exploring the molecular adhesion of ocular mucins. Biomacromol 2:498-503

[31] Jauvert E, Dague E, Severac M, Caminade A, Ressier L, Majoral J, Trevisiol E (2012) Probing single molecule interactions using biofunctionalized dendritips. Sens Actuators B Chem 168:436-441

[32] Li H, Jia Y, Feng X, Li J (2017) Facile fabrication of robust polydopamine microcapsules for insulin delivery. J Colloid Interface Sci Elsevier Inc 487:12-19

[33] Farrugia A (2010) Albumin usage in clinical medicine: tradition or therapeutic? Transfus Med Rev 24:53-63

[34] Chassepot A, Ball V (2014) Human serum albumin and other proteins as templating agents for the synthesis of nanosized dopamine-eumelanin. J Colloid Interface Sci 414:97-102

[35] Koutsopoulos S, Patzsch K, Bosker WT, Norde W (2007) Adsorption of trypsin on hydrophilic and hydrophobic surfaces. Langmuir 23:2000-2006

[36] Diao J, Ren D, Engstrom JR, Lee KH (2005) A surface modification strategy on silicon nitride for developing biosensors. Anal Biochem 343:322-328

[37] Xu L, Yamamoto A (2012) Characteristics and cytocompatibility of biodegradable polymer film on magnesium by spin coating. Colloids Surf B 93:67-74

[38] Zhang L, Zheng G, Guo Y, Zhou L, Du J, He H (2014) Preparation of novel biodegradable pHEMA hydrogel for a tissue engineering scaffold by microwave-assisted polymerization. Asian Pac Trop Med 7:136-140
[39] Xie J, Zhong S, Ma B, Shuler FD, Lim CT (2013) Controlled biomineralization of electrospun poly( $\varepsilon$-caprolactone) fibers to enhance their mechanical properties. Acta Biomater 9:5698-5707

[40] Träger D, Pohle K, Tschirner W (1995) Anterior cruciate ligament suture in comparison with plasty. A 5-year followup study. Arch Orthop Trauma Surg 114:278-280

[41] Saito Y, Minami K, Kobayashi M, Nakao Y, Omiya H, Imamura H, Sakaida N, Okamura A (2002) New tubular bioabsorbable knitted airway stent: biocompatibility and mechanical strength. J Thorac Cardiovasc Surg 123:161-167

[42] Rim NG, Kim SJ, Shin YM, Jun I, Lim DW, Park JH, Shin H (2012) Mussel-inspired surface modification of poly (Llactide) electrospun fibers for modulation of osteogenic differentiation of human mesenchymal stem cells. Colloids Surf B 91:189-197

[43] Islam MR, Bach LG, Seo SY, Lim KT (2013) Immobilization of proteins onto poly(2-hydroxyethyl methacrylate) functionalized $\mathrm{Fe}-\mathrm{Au} / \mathrm{core}$-shell nanoparticles via adsorption strategy. J Nanosci Nanotechnol 13:603-606

[44] Zhou P, Deng Y, Lyu B, Zhang R, Zhang H, Ma H, Lyu Y, Wei S (2014) Rapidly-deposited polydopamine coating via high temperature and vigorous stirring: formation, characterization and biofunctional evaluation. PLoS ONE 9:e113087

[45] Ball V, Del Frari D, Toniazzo V, Ruch D (2012) Kinetics of polydopamine film deposition as a function of $\mathrm{pH}$ and dopamine concentration: insights in the polydopamine deposition mechanism. J Colloid Interface Sci 386:366-372

[46] Li H, Cui D, Cai H, Zhang L, Chen X, Sun J, Chao Y (2013) Use of surface plasmon resonance to investigate lateral wall deposition kinetics and properties of polydopamine films. Biosens Bioelectron 41:809-814

[47] Hong Z, Chasan B, Bansil R, Turner BS, Bhaskar KR, Afdhal NH (2005) Atomic force microscopy reveals aggregation of gastric mucin at low $\mathrm{pH}$. Biomacromol 6:3458-3466

[48] Lyubchenko YL, Shlyakhtenko LS, Harrington RE, Oden PI, Lindsay SM (1993) Atomic force microscopy of long DNA: imaging in air and underwater. PNAS 90:2137-2140

[49] Vargaftik NB, Volkov BN, Voljak LD (1983) International tables of the surface tension of water. J Phys Chem Ref Data $12: 817-820$

[50] Fox HW, Zisman WA (1950) The spreading of liquids on low energy surfaces 1 Polytetrafluoroethylene. J Colloid Sci $5: 514-531$

[51] Good RJ, van Oss CJ (1992) The modern theory of contact angles and the hydrogen bond components of surface energies. In: Schrader ME, Loeb G (eds) Mod Approach to Wettability Theory Appl. Plenum, New York 
[52] Lamprou DA, Smith JR, Nevell TG, Barbu E, Willis CR, Tsibouklis J (2010) Towards the determination of surface energy at the nanoscale: a further assessment of the AFMbased approach. J Adv Microsc Res 5:137-142

[53] Mallinson D, Cheung DL, Simionesie D, Mullen AB, Zhenyu J (2016) Experimental and computational examination of anastellin (FnIII1c)-polymer interactions. J Biomed Mater Res A 105:737-745

[54] Sugawara Y, Ohta M, Konishi T, Morita S, Suzuki M, Enomoto Y (1993) Effects of humidity and tip radius on the adhesive force measured with atomic force microscopy. Wear 168:13-16

[55] Lynge ME, van der Westen R, Postma A, Städler B (2011) Polydopamine-a nature-inspired polymer coating for biomedical science. Nanoscale. 3:4916

[56] Ghobeira R, Philips C, Declercq H, Cools P, De Geyter N, Cornelissen R, Morent R (2017) Effects of different sterilization methods on the physico-chemical and bioresponsive properties of plasma-treated polycaprolactone films. Biomed Mater 12:15017

[57] Peña JA, Gutiérrez SJ, Villamil JC, Agudelo NA, Pérez LD (2016) Policaprolactone/polyvinylpyrrolidone/siloxane hybrid materials: synthesis and in vitro delivery of diclofenac and biocompatibility with periodontal ligament fibroblasts. Mater Sci Eng C Mater Biol Appl 58:60-69

[58] Zhuang P, Dirani A, Glinel K, Jonas AM (2016) Temperature dependence of the surface and volume hydrophilicity of hydrophilic polymer brushes. Langmuir 32:3433-3444

[59] Zhao J, Han W, Tang M, Tu M, Zeng R, Liang Z, Zhou C (2013) Structure, morphology and cell affinity of poly(1lactide) films surface-functionalized with chitosan nanofibers via a solid-liquid phase separation technique. Mater Sci Eng C 33:1546-1553

[60] Yang H, Fung S, Pritzker M, Chen P (2007) Modification of hydrophilic and hydrophobic surfaces using an ionic-complementary peptide. PLoS ONE 2:e1325

[61] Mallinson D, Alexiou P, Mullen AB, Pelecanou M, Sagnou M, Lamprou DA (2016) Isatin thiosemicarbazone-blended polymer films for biomedical applications: surface morphology, characterisation and preliminary biological assessment. RSC Adv 6:24939-24945
[62] Bujacz A (2012) Structures of bovine, equine and leporine serum albumin. Acta Crystallogr Sect D-Biol Crystallogr 68:1278-1289

[63] Greenfield NJ (2006) Using circular dichroism spectra to estimate protein secondary structure. Nat Protoc 1:2876-2890

[64] Bansil R, Turner BS (2006) Mucin structure, aggregation, physiological functions and biomedical applications. Curr Opin Colloid Interface Sci 11:164-170

[65] Manohar R, Gunasekaran K (2016) 5GXP - Cationic Trypsin With GOL/PGE as Dimer at pH 4.6 [Internet]. RCSB PDB. 2016 [cited 2017 Apr 27]. Available from: http://www.rcsb. org/pdb/explore.do?structureId=5GXP

[66] Manohar R, Kutumbarao NH V, Karthik L, Malathy P, Velmurugan D, Gunasekaran K (2016) 5JYI-Trypsin bound with succinic acid at 1.9A [Internet]. RCSB PDB. 2016 [cited 2017 Apr 27]. Available from: http://www.rcsb.org/ pdb/explore/explore.do?structureId=5jyi

[67] Greenfield N, Fasman GD (1969) Computed circular dichroism spectra for the evaluation of protein conformation. Biochemistry 8:4108-4116

[68] Wen X, Xiao Z, Jiang T, Li J, Zhang W, Zhang L, Shao H (2013) Constructing novel fiber reinforced plastic (FRP) composites through a biomimetic approach: Connecting glass fiber with nanosized boron nitride by polydopamine coating. J Nanomater 2013:470583. https://doi.org/10.1155/ 2013/470583

[69] Qbal Z, Lai EPC, Avis TJ (2012) Development of polymermodified magnetic nanoparticles and quantum dots for Escherichia coli binding test. Microchim Acta 176:193-200

[70] Sigma-Aldrich. Dopamine hydrochloride [Internet]. SigmaAldrich. 2017 [cited 2017 Feb 8]. Available from: http:// www.sigmaaldrich.com/catalog/product/sigma/h8502

[71] Ma J-X, Yang H, Li S, Ren R, Li J, Zhang X, Ma J (2015) Well-dispersed graphene-polydopamine-Pd hybrid with enhanced catalytic performance. RSC Adv 5:97520-97527

[72] Qiu T, Wang J, Lu Y, Yang W (2014) Facile fabrication of Chinese lantern-like $\mathrm{MnO} @ \mathrm{~N}-\mathrm{C}$ : a high-performance anode material for lithium-ion batteries. RSC Adv 4:23027-23035 